\title{
Inscrições da relação terapeuta-paciente no campo da terapia ocupacional*
}

\section{Inscriptions of therapist-patient relationship in the occupational therapy field}

\author{
Eliane Dias de Castro ${ }^{1}$
}

\begin{abstract}
CASTRO, E. D. de. Inscrições da relação terapeuta-paciente no campo da terapia ocupacional. Rev. Ter. Ocup. Univ. São Paulo, v. 16, n. 1, p. 14-21, jan./abr., 2005.

RESUMO: Ao refletirmos sobre a relação terapeuta-paciente no campo da terapia ocupacional na contemporaneidade, identificamos práticas e conceitos que estabelecem inovações e acontecimentos que abrem espaços numa multiplicidade de territórios da vida. Na terapia ocupacional a relação terapeuta-paciente está inscrita num campo de complexidades no qual questões relacionadas ao sofrimento humano exigem estudos e conhecimentos interdisciplinares. Isto sugere uma construção gradual e artesanal das práticas e o engendramento de saberes locais. Os terapeutas ocupacionais atuam nas disfunções que se manifestam em diferentes áreas da vida de sujeitos que por diversas razões foram impedidos de prosseguir formando linhas narrativas potencializadas pela experiência do viver. O conteúdo teórico e reflexivo aqui desenvolvidos estabelece interconexões com práticas contemporâneas nas quais composições compartilhadas por pacientes e terapeutas orientam a construção de uma ética que atravessa todos os momentos deste encontro.
\end{abstract}

DESCRITORES: Terapia Ocupacional/tendências. Prática profissional/tendências. Relações profissionalpaciente.

\footnotetext{
* Seleção parcial dos estudos teóricos realizados para o desenvolvimento do projeto de pesquisa: Corpo e Arte: articulando ações em Terapia Ocupacional, Relatório FAPESP, no período de 2003 - 2005, desenvolvido junto ao Programa Permanente Composições Artísticas e Terapia Ocupacional do Laboratório de estudos e pesquisa Arte e Corpo em Terapia Ocupacional da USP.

${ }^{1}$ Docente do Curso de Terapia Ocupacional do Departamento de Fisioterapia, Fonoaudiologia e Terapia Ocupacional da Faculdade de Medicina da USP. Mestre em Artes e Doutora em Ciências da Comunicação pela Escola de Comunicações e Artes da USP.

Endereço para correspondência: Departamento de Fisioterapia, Fonoaudiologia e Terapia Ocupacional. Rua Cipotânea, 51. Cidade Universitária. CEP: 05360-000. São Paulo, SP.
} 


\section{INTRODUÇÃO}

A relação terapeuta-paciente tem para a terapia ocupacional contemporânea um lugar de renovação de gestos, ações e sentidos, um lugar de reflexão. No encontro entre terapeutas e pacientes ocorre a tessitura das práticas, das propostas de tratamento, do exercício da terapia ocupacional. A partir deste encontro muitas inquietações, novas percepções e todo um redimensionamento e uma inovação da profissão vem sendo possível. É, neste lugar que se originam muitos acontecimentos, matérias de novos sentidos existenciais que tocam tanto os terapeutas quanto os pacientes e abrem espaços numa multiplicidade de territórios - visíveis e invisíveis, materiais e imateriais, objetivos e subjetivos, teóricos, técnicos, tecnológicos e metodológicos, conteúdos que inscrevem fundamentalmente a emergência do humano, e afetam todos os atores deste encontro. Ela desenvolve-se num campo de complexidades no qual questões relacionadas ao sofrimento humano exigem estudos e conhecimentos interdisciplinares - técnico-científicos, antropológicos, psicológicos, sociais, filosóficos e políticos - que caracterizaram a necessidade de ampliação da atuação do terapeuta ocupacional e de operarmos com uma compreensão do ser humano que possa atravessar as fronteiras do pensamento e das ações e construir novos lugares para a vida que se processa, para o inusitado das demandas que se constelam nos encontros. No campo das práticas em terapia ocupacional no Brasil, os terapeutas ocupacionais muitas vezes deparam-se com questões singulares que nos transportam para uma não convencionalidade clínica - questões do cotidiano e da organização das vidas nos surpreendem e nos desafiam. Acompanhar as ações de sujeitos com histórias complexas nos remete a um campo de inventividade, de criatividade, de singularidades, de contato com culturas diversas, de heterogeneidades e relaciona-se à construção do acesso às múltiplas informações que diferentes áreas, como por exemplo, da Reabilitação, da Saúde, da Educação e de outros campos do conhecimento podem proporcionar. São necessidades que atuam sobre a disposição técnica dos terapeutas ocupacionais e solicitam renovações no campo conceitual para ampliar ações e a compreensão das pessoas atendidas.

Para embasar teoricamente este contexto no qual a relação terapeuta-paciente se inscreve articulamos autores e proposições teóricas que conectam necessidades clínicas, sociais e ambientais, proporcionando assim uma reflexão sobre a forma de receber e de compreender o ser humano, sua organização, as relações sociais e a vida. Operamos sempre num terreno da vida, em sua formatividade, em sua afetividade e pulsação. A terapia ocupacional não sobreviverá se nos deixarmos aprisionar pelos formatos frios de práticas reducionistas que se contentam em proporcionar um aparato técnico sem olhar, a partir do microcontexto onde se dá a relação terapeuta-paciente, para toda a gama de necessidades que podem estar condensadas nas demandas tecnicistas. Se pensarmos a saúde, como na indicação de Basaglia (1982, p. 418) como produção de vida, a relação terapeuta-paciente implicará numa multiplicidade de ações e intervenções no mundo.

Ao pensarmos esta relação veremos que todos os fios que no princípio nos conduzem passam inegavelmente por lugares da renovação ética, da construção dos direitos e das políticas em saúde que direcionam ou podem orientar este encontro. A relação terapeuta-paciente designa um lugar de conexão entre a ética, a política e o direito, designa uma costura capaz de reforçar as passagens entre autonomia pessoal e vínculo social. Perceber o ser vivo em constituição, em processo, "tendo como princípio as conexões que o constituem ao longo de sua existência" (SANT'ANNA, 2001, p. 88).

Ao iniciarmos a construção de um pensamento e de uma reflexão sobre esta relação nos deparamos com a extensão do tema, e com a pluralidade do campo assistencial no qual se enraíza a terapia ocupacional contemporânea, e em especial com as características da população atendida neste campo no Brasil, o que nos remete ao cuidado em não produzirmos muitas generalizações. Buscamos organizar um alinhamento de idéias pinçadas nas experiências diretas no atendimento de pessoas em terapia ocupacional, em referenciais bibliográficos que promovem consistência às ações práticas e no trabalho de acompanhamento de estudantes de Graduação em Terapia Ocupacional. É importante enfatizar que cada terapeuta, dependendo do campo e área de atuação terá que realizar as adaptações de saberes e práticas de acordo com as necessidades e questões apresentadas pelos sujeitos atendidos. Isto sugere uma construção gradual, artesanal, e no engendramento de saberes locais, há de se avaliar cada situação em particular e a qualidade da demanda terapêutica que está em questão. Os terapeutas ocupacionais atuam nas disfunções que se manifestam em diferentes áreas da vida de sujeitos que por diversas razões foram impedidos de prosseguir formando sua própria história na multiplicidade de linhas narrativas proporcionadas pela experiência do viver.

\section{Atenção e acolhimento}

A delicadeza é a forma sadia de relação com o outro que 
apresenta sinais de sofrimento. "Sofrerei portanto com o outro, mas sem me apoiar, sem me perder. A essa conduta, ao mesmo tempo muito afetiva e muito vigiada, muito amorosa e muito policiada, pode-se dar um nome: é a delicadeza: ela é como a forma sã (civilizada, artística) da compaixão" (BARTHES, 1981, p. 49 apud FRAYZE-PEREIRA, 1995, p.107).

$\mathrm{Na}$ formação do terapeuta ocupacional, estudos, discussões, observações, vivencias e práticas formam camadas de consistência, construindo atitudes, preparando para um encontro consciente e responsável entre alguém que vai optando e se abrindo para receber e acolher de uma maneira especial e singular um outro alguém que traz em sua história intensidades, rupturas, demandas ou ausência de demandas, que muitas vezes não temos como saber se estamos preparados para acolher. $\mathrm{Na}$ atividade profissional esta responsabilidade pelo outro é estruturada continuamente, de forma dinâmica, a cada encontro com a população atendida.

Selecionamos dois acontecimentos, dois atos inaugurais que nos guiam nos primeiros momentos do encontro entre paciente e terapeuta: atenção e acolhimento são dois gestos que fundam a tensão em direção ao outro. Nestes gestos inicia-se uma responsabilidade confiada onde alguém é preparado especialmente para acolher um outro alguém cuja demanda de atenção relaciona-se a uma multiplicidade de necessidades e de questões. A atenção $e$ $o$ acolhimento determinam o receber, a receptividade do receber o outro como relação ética. E depende também essencialmente do sim do outro, não menos que o sim ao outro (DERRIDA, 2004, p. 52). Podemos entender então estes dois gestos inaugurais como primeiros movimentos que expressam uma simultaneidade de atividade e passividade tanto daquele que recebe alguém e daquele que é acolhido. Nestes primeiros movimentos todas as singularidades que marcam a vida do paciente estão presentes: características biológicas, potencialidades psíquicas, sua história, suas marcas, experiências anteriores de socialização, sua cultura - estruturas e desestruturas que dão formas à vida de todos nós. Estes fatores fazem com que cada pessoa atendida necessite de um tipo de cuidado que "só poderá ser ministrado por alguém que esteja, frente a ele e seu desenvolvimento, em um estado de devoção e de relação empática" (SAFRA, 1995 apud BARRETO, 2000, p. 7).

Nos momentos iniciais dos atendimentos estão envolvidos também, vários aspectos relacionados à pessoa do terapeuta: a corporeidade, os sentidos, as percepções, as formas de expressão, a organização da escuta, os cuidados com os tempos e os espaços, as observações, as proposições teóricas e práticas, as experiências culturais, sua história de vida - são matérias da experiência de vida que conferem qualidade nestes gestos fundantes da relação terapeuta-paciente.

A atenção e o acolhimento nos remetem à imagem de uma porta, de uma passagem, momento em que se abre no relacionamento com o outro uma maneira de falar, de escutar, de proceder. A 'porta aberta' designa a acessibilidade a um campo de conhecimento, no qual o terapeuta ocupacional operará como um interlocutor do sujeito frente a todo um aparato técnico-científico, social e ambiental, acompanhando-lhe na construção de formas de lidar com questões que poderão constituir um entendimento de sua saúde e dos recursos e direitos que lhe conferirão transformações no seu modo de viver e no contexto em que se desenrola sua vida. Podemos pensar esta relação como uma relação ética com uma demanda acolhida dentro de um campo de direitos e de um conjunto de políticas referente aos atendimentos em saúde, em terapia ocupacional. A relação terapeuta-paciente poderá ser compreendida como um dispositivo que nos remete a muitas questões filosóficas, ético-políticas, sociais, psicológicas e ambientais - que com todo o cuidado necessário, é preciso respeitar a qualidade desta relação, com a "urgência de uma ética exercida cotidianamente” (SANT’ ANNA, 2001, p. 88).

Nos movemos num território onde a matéria deste encontro funde mundos - terapeuta e paciente, estarão imersos numa temporalidade nova dada pelas formas de organização, necessidades, histórias e experiências do paciente, complementadas por uma tessitura na qual ambos vão afetando-se mutuamente, progressivamente, criando, como nas concepções de Winnicott (1975), uma realidade compartilhada constituída de matéria afetiva.O fundamental é que nesta relação seja possível ao paciente existir como ser humano apesar das doenças, deficiências e dos sofrimentos que o afligem. Neste encontro, o paciente inscreve as suas características na subjetividade do terapeuta, o que lhe permite desenvolver um sentido de continuidade e um certo estilo de ser (SAFRA, 1995 apud BARRETO, 2000, p. 7).

Nesta trama identificamos um conteúdo consciente e sensível que nutre o pensamento, a linguagem, a compreensão de estados clínicos, que se complexificam, que proporcionam a continuidade do relacionamento e as entradas nas redes sociais. Nos desdobramentos das ações compartilhadas e desenvolvidas nestes encontros, conhecimentos são transformados em formas de vida. Lugares da subjetividade de cada ator deste relacionamento são tocados e ocorre uma remodelação na geografia da subjetividade de ambos - os encontros formam novas 
subjetividades, permitem o trânsito por novos territórios, orientam novas formas de compreender o vivido, criam aberturas em direção aos outros e ao mundo que nos envolve. Identificamos também uma outra matéria, absorvida inconscientemente que aparecem nas fantasias, nos sonhos, nas imagens de devir, nas dificuldades e entraves cotidianos, nos ires e vires do processo terapêutico engendrado por esta dupla. Alguns projetos e campos formativos podem surgir como ressonâncias do não completamente compreendido, daquilo que necessita ser aprofundado ou, melhor estudado. Nas narrativas dos pacientes e dos terapeutas ocupacionais, múltiplas formas destas experiências são relatadas, o material inconsciente também possibilita novos entendimentos e direcionamento das ações e procedimentos terapêuticos e da condução da própria relação. Este material inconsciente afetará este encontro, o movimentará, participará da fiação da vida, da inscrição de ações e criações no mundo.

A atenção e o acolhimento solicitam do terapeuta ocupacional o trânsito por matérias de sensações, por terrenos sensíveis, e a abertura para uma corrente de fluxos, com a disposição para atravessar fronteiras de diversas ordens e configurações, e situar-se cooperativamente como força viva para a transformação da vida humana. Existe aqui uma dupla necessidade: a de que se exerça junto aos sujeitos atendidos, determinadas funções ambientais que possam colocar em marcha seu desenvolvimento, e por outro lado existe também a necessidade de se trabalhar no ambiente, no território da cidade onde transcorre a vida, também de forma artesanal para favorecer estratégias de terapia ocupacional que permitam ao paciente produzir valor social, produzir novos sentidos para sua existência.

\section{VÍNCULO}

Podemos agora pensar sobre o processo de vinculação que se estabelece na relação terapeuta-paciente no campo da terapia ocupacional e em outras áreas da promoção da saúde ou da vida, onde este encontro ocorre. O contato entre dois seres humanos é uma experiência potente que definirá o mundo imediato no qual este contato se estabelece. É assim que cada um de nós se defronta com um outro, o vínculo com alguém é imprescindível para o acontecer humano. $\mathrm{O}$ outro interage conosco, responde ou não às nossas ações e, por sua vez, provoca respostas em nós. Nossa humanidade básica depende desse sentimento de ligação, desta experiência vincular. Um vínculo se estabelece através de um sistema de poderosas conexões - superfícies corporais, linguagem, olhares, sentimentos, fazeres, constância, intensidades, intimidade emocional, são algumas formas de sua manifestação. $\mathrm{O}$ trabalho terapêutico ocupacional oferece uma oportunidade ímpar para que esse processo ocorra, nele, experiências vinculares anteriores do paciente poderão ser dinamizadas pela presença e pelas intervenções do terapeuta. Nesta relação, a observação atenta, a experiência do olhar, o olhar o rosto, o olhar os olhos, o contato, a escuta, complementada com a qualidade de atenção, acolhimento e presença, configuram campos de ações entre pacientes e terapeutas. O vínculo se constrói na experiência interpessoal do relacionamento que vai se estabelecendo, e nele um processo de identificação ocorre: qualquer pessoa "sente e age como uma outra pessoa e faz desta, de certo modo, parte de si mesma” (STERN, 1991, p. 59).

É no processo de vinculação que se forma a capacidade essencial para a identificação. Esta capacidade se dá num primeiro momento quando a pessoa imita quase que automaticamente as expressões faciais e gestos de outros; e, concomitantemente, ela é suscetível ao contágio emocional do outro: "o estado emocional de outra pessoa invade você, por assim dizer, estabelece uma emoção responsiva dentro de você" (STERN, 1991, p. 60). Paciente e terapeuta viverão uma experiência singular, uma experiência compartilhada que favorece uma aproximação, que "não é semelhante a qualquer outra experiência interpessoal. Você parece sentir e acompanhar vagamente a vida mental do outro" (STERN, 1991, p. 60).

No vínculo terapeuta-paciente desencadeia-se um contágio da excitação e uma vitalidade, coloca-se em andamento um processo, no qual pode ocorrer um ligeiro descompasso que desencadeia uma reação - ao permanecerem fora de sincronização paciente e terapeuta “incitam um ao outro" como num jogo de desvelamento, de revezamento, de interação social. Na experiência do vínculo abre-se a possibilidade do paciente pensar em termos de si mesmo tomando iniciativa para atingir um objetivo. O paciente no interjogo do relacionamento tem a possibilidade de construir uma noção de si mesmo como autor de suas próprias ações e de suas ações tendo consequiências previsíveis. Sente-se como agente numa cadeia causal de eventos. Ele experimenta repetidas vezes ações e tem respostas: o desejo, a ação, a execução, o objetivo - tudo isto acontecendo junto no vínculo forma momentos de criação mútua. Eles são a essência da convivência, do estar com outra pessoa, do estar e ser no social.

Vemos como certas atitudes do terapeuta podem abrir todo um campo de experimentações para o paciente no qual ele começa a vislumbrar novos horizontes, novas possibilidades de existir no mundo. O vínculo terapeuta-paciente faz um intenso convite para um envolvimento mais vigoroso 
com os outros e com o mundo. O comportamento do terapeuta no campo vincular, muitas vezes é intuitivo e ganha formas e funções diversas e variadas. O terapeuta trabalha manejando a intensidade dos estímulos, acertando o pulso na possibilidade do paciente, construindo experiências compartilhadas de diferentes ritmos, de diversas qualidades, ajustando o próprio comportamento e ações a outras temporalidades, engendradas pelas potencialidades do paciente. Ele age em constante feedback, e com isso saberá o que fazer e quando, facilitando os investimentos do paciente no mundo sem forçá-los. Neste processo, o terapeuta inevitavelmente cometerá erros, necessários e potencialmente de grande valor, pois ajudam o paciente no desenvolvimento de seus próprios modos de lidar com uma variedade de experiências e pessoas. Erros não se constituem como trauma ou uma tragédia. Terapeuta e pacientes têm a possibilidade de cuidarem bastante bem da situação, e no processo, novamente estarem prontos para uma nova interação.

O trabalho vincular da relação terapeuta-paciente deverá abrir para uma maturação vincular. É através dos diferentes vínculos que o impulso de apego matura-se. Para Bolwby (1985), o 'attachment' maturado (instinto de apego) produz a capacidade de ir muito longe, de criar e transitar em vários territórios, de produzir vários vínculos no mundo. São situações que exigem tempo, ritmo, ações, passo a passo. Nas narrativas vinculares exercitamos muitos graus entre o apegar-se e o desapegar-se. E, neste contexto, os terapeutas buscarão atualizar o trabalho terapêutico ao que interessa ao paciente no momento do tratamento. É no vínculo terapeuta-paciente que estas possibilidades se reatualizam e se complexificam. Afinar e refinar a existência, possibilitar o amadurecimento vincular, criar distinções/ aprofundar, favorecer experiências de aproximação e intimidade, ampliar os espaços de liberdade fundamentalmente proporcionar relações consigo mesmo, com o outro, e com o ambiente onde se vive, são aspectos que constituirão e definirão o trabalho vincular entre pacientes e terapeutas no campo da terapia ocupacional.

\section{HOLDING, CONTINÊNCIA E PROCESSO TERAPÊU- TICOOCUPACIONAL}

No decorrer do processo de vinculação no qual a relação terapeuta-paciente está se desenvolvendo, as funções de 'holding' e continência, são importantes funções de amparo e de sustentação exercidas pelos terapeutas e também por muitas outras pessoas no mundo e que se referem ao apoio através de uma presença, de um estar-junto, de uma sustentação física e emocional que uma relação vincular pode oferecer.

Winnicott (1975) denominou de holding (ou de sustentação) a tudo que, no ambiente, fornecerá a uma pessoa a experiência de uma continuidade, de uma constância tanto física quanto psíquica, que exercida continuamente possibilitará uma integração interna facilitadora da compreensão dos acontecimentos vividos. A proximidade dos dois corpos, mas fundamentalmente, a presença de um corpo atento, de um corpo habitado, um corpo que carrega a história do próprio vínculo, produz uma experiência integradora, pois neste sentido o sujeito está sendo acompanhado por um corpo vivo, potencializado e simbólico (simbolizado e simbolizante), e não somente matéria física. No desenvolvimento da relação terapeutapaciente, a presença física e psíquica ganha uma tonicidade afetiva, dada a possibilidade do terapeuta estar em contato com o paciente numa atitude empática. Esta atitude empática refere-se à estabilidade e constância nas atitudes do terapeuta, e à possibilidade do terapeuta se manter atento às necessidades dos pacientes ao longo do tempo (BARRETO, 2000, p. 63).

A presença de outro ser humano acompanhando as experiências de alguém faz com que marcas sensoriais sofram um processo de humanização, proporcionando à experiência uma compreensão e um pertencimento cultural. Esta continuidade proporcionada pelo holding (ou pela sustentação) é dada pelo respeito ao ritmo, num primeiro momento pela não interferência na ação do sujeito, e posteriormente, auxiliando-o a agir naquilo onde seu desejo ou sua necessidade o levarem, o que aponta para a possibilidade do paciente encontrar-se e integrar-se no tempo. Neste sentido, é esta possibilidade do terapeuta estar com o paciente ao longo do acontecimento que oferece a oportunidade de integração da experiência a fim de dar continuidade ao seu processo vital. A constância da sustentação fornece ao indivíduo a confiança na realidade e nos contatos humanos (BARRETO, 2000, p. 61).

Simultaneamente a esta função o terapeuta exercerá também a função da continência. Ela é a capacidade de um terapeuta, de um familiar, ou de qualquer pessoa - de transformar pela imaginação as experiências de um sujeito.

O homem precisa intermediar suas experiências - afetivas, pulsionais, existenciais e outras - do contrário, estas experiências podem ser disruptivas, pois o sujeito passa a viver o horror de não mais sentir um impulso, mas ser este impulso (BARRETO, 2000, p. 71). 
CASTRO, E. D. de. Inscrições da relação terapeuta-paciente. Rev. Ter. Ocup. Univ. São Paulo, v. 16, n. 1, p. 14-21, jan./abr., 2005.

Para Safra (2003), o percurso pela vida nos afeta e o indivíduo encontra em sua história rupturas que o impedem de se constituir.

São rupturas que acontecem em suas necessidades mais fundamentais, tais como a necessidade do outro, de comunicação, do olhar do outro, do encontro de um lugar no mundo, da realização de uma contribuição para o mundo (SAFRA, 2003, p. 56).

A função de continência é exercida pela capacidade de nomear ou encontrar imagens que veiculam experiências e sentimentos que nos habitam, mas que muitas vezes não somos capazes de expressar. Essa função exercida pelo terapeuta na relação terapeuta-paciente será gradualmente exercida pelo próprio indivíduo à medida que a sua capacidade para pensar e lidar com suas experiências é colocada em marcha.

As duas funções, holding e continência, se complementam, porém, se não é possível oferecer uma boa qualidade destas funções há o perigo do trabalho torna-se adaptativo, como ocorre tantas vezes nas práticas da terapia ocupacional. Para que isto seja potencializado, os terapeutas ocupacionais precisam aprofundar seus estudos nas teorias que se aprofundam na relação terapeuta-paciente e nas vicissitudes das construções vinculares, de forma a favorecer estas funções e a condução do processo terapêutico. As crises, sintomas e/ou paralisações no desenvolvimento dos sujeitos apontam também para dimensões da existência humana, ainda pouco ou nada simbolizadas. Em cada um de nós existem dimensões mais simbolizadas que outras e até mesmo áreas que, na nossa história de vida, não foram passíveis de simbolização. Podemos dizer que uma das funções do terapeuta é suprir uma ou várias falhas ambientais, isto leva nossa atenção ao fato de que todos possuímos áreas onde faltou uma experiência com outro ser humano que pudesse simbolizar uma determinada questão existencial. Contudo, não podemos afirmar que todas as falhas podem ser remediadas, pois em certas dimensões as seqüelas podem ser irreparáveis.

Nas ações em terapia ocupacional procuramos oferecer ao sujeito experiências que possam suprir determinadas fendas na experiência de estar vivo. Essas fendas podem ser decorrentes de inúmeros fatores, que poderíamos resumir como desencontros com as necessidades de um sujeito que, inevitavelmente, ocorrem ao longo da vida de cada um. O terapeuta ocupacional utilizará o potencial terapêutico presente no cotidiano da vida do sujeito, a fim de engendrar a continuidade de seu desenvolvimento. Pensar que no processo terapêutico ocupacional, muitas necessidades reais que ficaram desatendidas no passado do paciente, precisam ser percebidas, assinaladas e atendidas pelo terapeuta. Fazer intervenções que dêem elementos ao paciente para substituir os modos do passado pelas necessidades do presente, corresponde aos momentos potencializadores de mudanças no processo terapêutico ocupacional. Estas são cenas freqüentes no campo da terapia ocupacional, expressas nas seguintes ações: construir novas experiências vinculares, possibilitar ou refazer experiências, agenciar ações no mundo, auxiliar no processo de completar entendimentos, clarear processos vivenciados, sustentar a formulação dos desejos, gerar demandas, reorganizar espaços e tempos, construir novas redes de convívio e de existência.

Ora, na terapia ocupacional a atenção do terapeuta estará em parte investida nos movimentos psíquicos, no desenvolvimento mental, na recuperação afetiva, mas, por outro lado, no acompanhamento na realização das atividades e na construção de projetos singulares, o terapeuta trabalhará também no engendramento de processos educativos e socializantes que estarão a serviço da sobrevivência, da produtividade, da reprodutividade social e da imersão cultural. De forma ampla, o terapeuta ocupacional precisará dispor de recursos teóricoconceituais para trabalhar na relação terapeuta-paciente desfazendo obstáculos e estabelecendo condições para as integrações singulares e para as mudanças necessárias, facilitando aos pacientes o reconhecimento de si, sua capacidade de simbolizar e de pensar as experiências de vida, permitindo entrar em contato com suas necessidades e aprender a atendê-las primeiramente com a ajuda do terapeuta, e gradativamente promovendo uma possibilidade de auto-agenciamento no mundo. Neste sentido entendemos que o acompanhamento do desenvolvimento dos sujeitos no campo da terapia ocupacional soma experiências de preparo da sobrevivência e participação social interdependentes ao desenvolvimento pessoal, e este é função do desenvolvimento da realidade psíquica e da integração consigo mesmo, que abre campos para o enraizamento no enfrentamento dos processos de exclusão/ inclusão social.

Desta forma, o processo terapêutico ocupacional, na sua expressão, se configura numa ampla plasticidade, e refere-se ao estabelecimento de contratos de trabalho que se estabelecem e que se flexibilizam, sendo alterados no decorrer das necessidades e das novas composições que emergem nos atendimentos - horários preestabelecidos são acordados conjuntamente e de comum acordo; o tempo dos encontros também são previamente acordados, sendo que alguns trabalhos necessitam de um tempo suficientemente expandidos para que possam ser realizados; 
como os objetivos dos atendimentos de terapia ocupacional relacionam-se à construção de projetos singulares para a reconfiguração do cotidiano e de desenvolvimento das diferentes áreas da vida, estes podem variar no decorrer da realização dos atendimentos, e serão também acordados mutuamente a cada etapa do processo terapêutico; o trabalho, portanto, poderá ser realizado em diferentes espaços ou territórios onde transcorrerá a vida de cada paciente. Os números de encontros semanais também poderão variar de acordo com as demandas, necessidades e possibilidades dos pacientes e de acordo com o projeto desenvolvido com cada pessoa ou grupo. Assim, no decorrer de projetos singulares que constituem o processo de atendimento, este poderá ganhar formas mais ou menos contornadas, tecidos mais ou menos formados. Nas práticas contemporâneas da terapia ocupacional, áreas da vida dos sujeitos somam-se, agrupam-se, sobrepõem-se e transformam-se, numa plasticidade constante:

\begin{abstract}
"o corpo e sua funcionalidade, o conjunto de necessidades expressas e identificadas, a produção de sentido e significado para as ações e atividades, as diversas formas de vida criativa e produtiva, a organização e os cuidados dos tempos e dos espaços, o cotidiano, os cuidados pessoais, a circulação no território, a autonomia, a inclusão sociocultural, a convivência e a idéia de potencialização de redes, enfim, toda uma variabilidade de ações e de criações no mundo e de organização da vida participam nesta composição" (CASTRO et al., 2004, p. 70).
\end{abstract}

Este amplo exercício de leitura e compreensão de passagens clínicas revela as estratégias arrojadas de manejo clínico que as práticas da terapia ocupacional na contemporaneidade muitas vezes exigem e a qualidade da presença humana nestas funções. O término do processo terapêutico ocupacional é realizado de comum acordo entre pacientes e terapeutas, quando se considera que os objetivos do trabalho foram alcançados e que o paciente pode dar prosseguimento em seu processo de continuidade existencial no mundo de forma um pouco mais independente, com autonomia, com mais liberdade, participando de redes que agenciam sua vida, suas diferenças e singularidades.

\section{PASSAGENSÉTICAS}

Nas composições compartilhadas nesta relação a adoção e a construção de uma postura ética atravessa todos os momentos do encontro desta dupla e pode ser compreendida como "uma abertura para a passagem, para o acontecimento, no encontro com as singularidades que emergem da população que atendemos" (INFORSATO, 2005, p. 39). A ética que estamos mencionando é uma construção artesanal que abre possibilidades para permitir ao paciente experimentar a “intermitência de seu sofrimento" numa clínica que produza trocas entre os pacientes, enquanto estão sofrendo, com outras pessoas (SARRACENO, 2001, p. 30).

Ao compreendermos os sujeitos em constituição, ou em processo, formando-se nos acontecimentos que o constituem ao longo de sua existência, configuraremos um território potente de resistência cotidiana para os enfrentamentos propostos nas práticas em terapia ocupacional. Estabelecer um ambiente de atenção às pequenas transformações cotidianas, potencializam ações que dizem sobre uma fundamental conexão contra um sistema de dominação e exclusão sustentada por antigas concepções totalizantes. É esta ética que atravessará a relação terapeuta-paciente, num exercício cotidiano da construção do novo. Não se trata de uma conduta prédada, pois tal tarefa relaciona-se com o trabalho constante de distinguir complexos problemas antigos e também contemporâneos da relação entre dominantes e dominados. $\mathrm{O}$ respeito à vida e às relações aparecem como questões de sobrevivência individual e coletiva. A diversidade dos modos de existência dos seres marca as diferenças e as múltiplas possibilidades de composições singulares, que não precisam "dominar ou ser dominados para adquirirem importância e força” (SANT' ANNA, 2001, p. 95).

A relação terapeuta-paciente precisa ser cuidada para não ser inscrita nas relações de dominação, não reproduzindo com os pacientes um funcionamento no qual estes se situem como objeto desta relação. Sem excluir as forças e as diferenças entre os sujeitos em contato, a relação terapeuta-paciente ressoará mantendo ambos os sujeitos como agentes de uma composição formativa frente aos acontecimentos, com diferenças, promovendo um mútuo fortalecimento das vidas em conexão. $\mathrm{O}$ terapeuta ocupacional participa plenamente desta transformação cultural nas práticas contemporâneas, constituindo criticamente um novo papel profissional. Atuando como interlocutores da população atendida, adquirem um papel fundamental no cuidado e na afirmação da vida destas pessoas, engendrando com os pacientes, possibilidades de ação e criação no mundo contemporâneo.Trata-se de relacionar forças, ampliar as ressonâncias, realçando ao mesmo tempo o indivíduo e o coletivo, o humano e o não-humano, não para colocá-los acima da vida, mas dentro dela, estando atento ao fluxo 
CASTRO, E. D. de. Inscrições da relação terapeuta-paciente. Rev. Ter. Ocup. Univ. São Paulo, v. 16, n. 1, p. 14-21, jan./abr., 2005.

das coisas e ao potencial de cada acontecimento. As condutas éticas são criadas junto à habilidade de agir, de ser ação no mundo, de realizar conexões no mundo e com a vida sem degradá-la e sem degradar a condição humana. Isto pressupõe um cultivo destas novas orientações éticas, atualizadas cotidianamente.

CASTRO, E. D. de. Inscriptions of therapist-patient relationship in the occupational therapy field. Rev. Ter. Ocup. Univ. São Paulo, v. 16, n. 1, p. 14-21, jan./abr., 2005.

\begin{abstract}
Reflecting about the relationship between therapist-patient in the contemporary occupational therapy field, we identify practices and concepts that set up innovation and events that open spaces in a multiplicity of life territories. In occupational therapy the relationship between therapistpatient is inscribed in a complexity field in which questions related to human suffering demanding studies and interdisciplinary knowledge. It suggests a craft and gradual construction of practices and local knowledge. Occupational therapists are acting in disfunctions that are manifested in different life areas of human beings that for many reasons were blocked to continue forming narratives lines potencialized by life experiences. The theoretical and reflective contents here developed establish interconections to contemporary practices in which shared compositions by patients and therapists orientate the construction of an ethics that crossed all moments of these meating.
\end{abstract}

KEY WORDS: Occupational therapy/trends. Professional practice/trends. Professional-patient relations.

\title{
REFERÊNCIAS
}

BARTHES, 1981, p. 49 apud FRAYZE-PEREIRA, J. A. Olho d'água. Arte e loucura em exposição. São Paulo: Escuta/FAPESP, 1995. p. 107.

BARRETO, K. D. Ética e técnica no acompanhamento terapêutico. Andanças de Dom Quixote e Sancho Pança. $2^{\mathrm{a}}$. ed. São Paulo: Unimarco, 2000.

BASAGLIA, F. Basaglia Scritti II 1968-1980. Dall'apertura del manicômio alla nuova legge sull' assistenza psichiatrica. Torino: Einaudi Paperbacks, 1982.

BOLWBY, J. Apego. In: BOLWBY, J. Apego e perda. Trad. Valtensir Dutra. São Paulo: Martins Fontes, 1985.

CASTRO, E. D. et. al. Análise de atividades: apontamento para uma reflexão atual. In: DE CARL, M. M. P.; LUZO, M.C. (Orgs.). Terapia ocupacional. Reabilitação física e contextos hospitalares. São Paulo: Roca, 2004. p. 47-73.

DERRIDA, J. Adeus a Emmanuel Lévinas. Trad. Fábio Landa. São Paulo: Perspectiva, 2004. (Coleção Debates)

FRAYZE-PEREIRA, J. A. Olho d'água. Arte e loucura em exposição. São Paulo: Escuta/FAPESP, 1995.

INFORSATO, E. A. Clínica barroca. Exercícios de simpatia e feitiçaria. 2005. 169f. Dissertação (Mestrado em Psicologia Clínica) - Pontifícia Universidade Católica de São Paulo, São Paulo, 2005.

SAFRA, G. Momentos mutativos em psicanálise. Uma visão winnicottiana. São Paulo: Casa do Psicólogo, 1995. p. 9.

SANT'ANNA, D. B. Corpos de passagem. Ensaios sobre a subjetividade contemporânea. São Paulo: Estação Liberdade, 2001.

SARRACENO, B. Libertando identidades. Da reabilitação psicossocial à cidadania possível. 2a . ed. Trad. Lucia Helena Zanetta, Maria do Carmo Rodrigues Zanetta, Willians Valentini. Belo Horizonte: Te Corá Ed/Instituto Franco Basaglia, 2001.

STERN, D. N. Diário de um bebê. O que seu filho vê, sente e vivencia. Trad. Daise Batista. Porto Alegre: Artes Médicas, 1991.

WINNICOTT, D. W. O brincar e a realidade. Trad. José Octávio de Aguiar Abreu, Vanede Nobre. Rio de janeiro: Imago Ed., 1975. 